\title{
Fragile Markets: An Experiment on Judicial Independence*
}

\author{
Benito Arruñada \\ and \\ Marco Casari
}

This version: May 27, 2016

\begin{abstract}
Contract enforcement does not only affect single transactions but the market as a whole. We compare alternative institutions that allocate enforcement rights to the different parties to a credit transaction: either lenders, borrowers, or judges. Despite all parties having incentives to enforce and transact, the market flourishes or disappears depending on the treatment: paying judges according to lenders' votes maximizes total surplus and equity; and a similar result appears when judges are paid according to average earnings in society. In contrast, paying judges according to borrowers' votes generates the poorest and most unequal society. These results suggest that parties playing the role of borrowers understand poorly the systemic consequences of their decisions, triggering under-enforcement, and hence wasting profitable trade opportunities.
\end{abstract}

Keywords: impersonal exchange, third-party enforcement, steps of reasoning, otherregarding preferences, judicial independence.

JEL codes: C91, C92, D53, D63, D72, K40

\footnotetext{
* Arruñada: Pompeu Fabra University and Barcelona GSE, Trias Fargas, 25, 08005 Barcelona, Spain, voice: +34 935422 572, fax: +34 935421 746, email: benito.arrunada@upf.edu; Casari: Universita' di Bologna, Department of Economics, Piazza Scaravilli 2, 40126 Bologna, Italy, voice: +39 051 2098662, fax: +39 051209 8493, email: marco.casari@unibo.it. Comments by the editor, Dirk Engelmann, two anonymous reviewers, Gabriele Camera, Guillaume Fréchette, Juanjo Ganuza, Luis Garicano, Henry Hansmann, Lewis Kornhauser, Steven Martin, Bill Novshek, Julian Rode, Cándido Paz-Ares, Albert Satorra and seminar and conference participants at AEA, Amsterdam, Bari, Carlos III, CLEF, EALE, Essex, FEDEA, Firenze Beelab workshop, FSU workshop, IMT, ISNIE, PUC, Purdue, and Siena, as well as research assistance from Jingjing Zhang and Sukanya Chaudury, are gratefully acknowledged. Usual disclaimers apply. Funding for this research was provided by Purdue University, the Spanish Ministry of Finance and Competitiveness, through grant ECO2014-57131-R, and the European Commission through Project CIT3-513420.
} 


\section{Introduction}

Markets are fragile because contract enforcement has immediate consequences for those who have entered contracts in the past but also has systemic consequences for all future potential contracts. Consider weak foreclosure enforcement. In the short run, it relieves borrowers; in the long run, it hinders mortgage lending and hence is prone to damage total surplus. Field evidence abounds: Field and Torero (2006) and Galiani and Schargrodsky (2010) documented several cases in developing countries and Alston (1984) illustrated the 1930s farm foreclosure moratoria adopted in 25 US states.

Through an experiment, we study third-party enforcement in impersonal exchanges under alternative enforcement institutions. If the party that controls enforcement has a poor understanding of the systemic consequences of its decisions, it may trigger insufficient enforcement, and hence waste exchange opportunities. At the heart of this study lies a question about social preferences. Do-gooders may jump in and redistribute the surplus in favor of those in need; or, they may take a cooler approach and consider the long-term welfare of those they want to benefit. Other-regarding concerns applied short-sightedly may cause overall damage to those who are supposedly the beneficiaries of decisions. This argument also involves issues of rationality. Laboratory experiments allow for investigation of these issues.

The experimental treatments we consider represent three institutional arrangements in which different classes of individuals hold the key decision rights. In the "GDP" treatment, we pay judges proportionally to the aggregate income of the economy. In contrast, in the "Lender constituency" and "Borrower constituency" treatments, we pay judges according to how close to the average vote of the constituency class they rule. In all treatments, judges have formal enforcement powers, as they are free to enforce or not, but in constituency treatments it is a different class of subject that controls enforcement. We therefore talk of allocating enforcement rights to different classes of subjects: to judges in the GDP treatment, ${ }^{1}$ to lenders in the Lender constituency treatment and to borrowers in the Borrower constituency treatment.

We report that simple experimental credit markets where parties interact repeatedly can flourish when enforcement is controlled by lenders or by a third party with an interest in aggregate surplus, but markets dry up when enforcement is controlled by borrowers. This result

\footnotetext{
${ }^{1}$ For simplicity, we talk about "judges", but the members of this class have a position that is also close to that of legislators.
} 
is a paradox because when borrowers are in control their earnings are lower than when lenders are in control.

In the GDP and Lender Constituency treatment, judges' enforcement is high and the number of loans is close to optimal. But, when borrowers control judges, enforcement falls below the threshold that would make lending profitable, and very soon no loans take place and the market disappears. In an attempt to appropriate more surplus, borrowers discourage future loans and end up damaging their own earnings. The paradox is that borrowers end up better, in terms of both absolute and relative income, when lenders control judges because lenders encourage enforcement and the economy achieves its full potential.

We explore three possible explanations for this stark contrast in outcomes: other-regarding preferences, bounded rationality, and coordination failures. To this end, the design was extended in two directions. First, we incorporated independent measures of individual rationality and other-regarding preferences that could be related to enforcement decisions. Second, there were design variants where some decision-makers were replaced by robots. In one variant, borrowers were human while lenders and judges were robots; in another variant, judges were human, while lenders and borrowers were robots. The purpose of robot treatments was to simplify the coordination of decisions, remove any possible influences of other-regarding concerns, and retain instead issues of bounded rationality. Although none of the three explanations mentioned above can be entirely ruled out, the evidence suggests that bounded rationality was the most relevant factor in the low performance of Borrower Constituency. We claim that subjects found it difficult to understand the systemic effects of their choices because of cognitive limitations. Given that Borrower Constituency is the most cognitively "difficult" treatment, we have the paradox of borrowers ending up worse off when they are most able to influence the action of judges. $^{2}$

One feature of the study is its focus on impersonal exchange, e.g. transactions where parties do not rely on information about the reputation and solvency of the other party. This type of transaction often relies on the support of institutions, in particular, State enforcement delivered by the judicial system (North, 1990, pp. 34-35, 1991; Wallis, 2009). The widespread lack of

\footnotetext{
2 There is evidence that people suffer cognitive failures in different domains (Camerer, 2003). If enforcers suffer similar failures, the allocation of enforcement rights may matter. This concern may seem minor since enforcers are experts, such as judges and politicians. However, experts in other fields also suffer biases (McNeil et al., 1982). Furthermore, some studies find that judges suffer from "anchoring," "hindsight," "overconfidence," "framing" and "representativeness" biases (Guthrie, Rachlinksi and Wistrich, 2001). As for politicians, their possible biases are added to those of citizens (Westen et al., 2006), who ultimately drive the incentives of politicians. Furthermore, it is politicians who design the incentives of judges. Thus, the cognitive dimension of the contract enforcement problem is ultimately defined by the ability of non-expert citizens to understand the problem.
} 
enforcement in developing economies compels traders to rely on personal exchange, which requires weaker institutional support than impersonal exchange and makes some transactions unfeasible, hence wasting opportunities (de Soto, 2000). The experiment rules out by design the possibility of personal exchange, for instance in the form of relational contracts (Johnson and McMillan, 2002), by hiding subject identifiers. Hence, if impersonal exchange cannot be sustained, markets collapse. This is intended to reflect the crucial role that impersonal exchange plays in economic development. The possibility to engage in impersonal exchange expands market size and hence opens new specialization opportunities, which are essential for economic growth (North and Thomas, 1973; Granovetter, 1985; North, 1990; Seabright, 2004).

Others have studied credit markets experimentally from different angles. Brown and Zehnder (2007) looked at the impact of individual records in relation to access to credit and repayment rates. Sharing information made a difference in one-shot transactions but not in repeated settings. Fehr and Zender (2009) showed that relational contracts were effective for the existence and performance of credit markets. They also showed that, in some ways, legal enforcement of repayments was a substitute for relational incentives. Instead, here we study a simpler version of credit markets with no uncertainty in project returns and no possibility of relational contracts. Bohnet et al. (2001) also studied a modified trust game in which failing to return triggers a costly litigation procedure with random ruling. In contrast, in our set-up decisions have no cost but are at the discretion of a human judge.

The paper is structured as follows. Section 2 presents the experimental design. Section 3 presents some theoretical considerations, detailing the different equilibria in both the one-shot and the indefinitely repeated game. Section 4 presents the main results of the experiment, chiefly that when borrowers enjoy enforcement rights they are trapped in an inferior equilibrium. Section 5 presents a couple of variations of the basic treatments designed to test alternative explanations. Section 6 analyzes possible explanations for the main results. Section 7 discusses the implications of the findings and then concludes.

\section{Experimental design}

Participants first performed two tasks to measure their other-regarding preferences and reasoning ability, and then faced the main task, which comprised several periods of interaction. Feedback on the initial tasks was given at the end of the session. There were three treatments, where third-party enforcers had different compensation schemes. In the main task, for each 
session we had 15 participants whom we randomly allocated to five groups of three subjects, with each of these three subjects playing different roles and retaining that same role for the whole session.

Each of these five groups played a modified trust game with a lender (trustor), a borrower (trustee), and a judge (third-party enforcer), ${ }^{3}$ in which all choices were binary, and there was a sort of final litigation stage. As Figure 1 illustrates, final earnings for (lender, borrower) could be either $(60,16)$ for saving (not trusting), $(67,33)$ for giving a loan that was repaid (repaid trust), or $(50,50)$ for giving a loan followed by default (betrayed trust). A borrower maximized earnings when she received a loan but defaulted. However, this outcome was not sustainable in the long run because lenders were likely to react by not lending, hence generating the lowest possible earnings for the borrower. In case of betrayed trust, a judge intervened to rule for repayment or default. (We describe judges' compensation schemes below.)

Each session (or economy) was expected to last 26 periods. After the first 20 periods, a subject was asked to roll a dice. If the result was a six, the session was over; otherwise it continued for another period. In each one of the next periods, this procedure was repeated. This indefinite duration avoided end-of-game effects.

Our interest focused on the long run and the systemic impacts of participants' decisions, and this is what guided the design. In particular, we made surplus generation deterministic and gave borrowers the option as to whether to return the loan or not. Introducing risk or project choice would have shifted the focus away from the core issue of immediate vs. systemic impact of enforcement. It would also have made the design more complex and difficult to understand and the results harder to interpret if the market collapsed.

We also designed the experimental economies in such a way that all exchanges were impersonal. In every period, subjects interacted in groups of one lender, one borrower and one judge. Session participants were randomly partitioned into groups, which were randomly rematched after each period. Because subjects could not observe the identity of others in their group, individual reputations were impossible to build. When assessing the expected enforcement rate, lenders must consider the decisions of all judges. In fact, there is a panel of judges in the economy and every default is assigned randomly to one judge. This design contrasts with field and lab settings where transactions can present a mix of personal and impersonal elements (Fehr and Zehnder, 2009).

\footnotetext{
3 The paper uses "lender," "borrower," and "judge" while in the experiment we used neutral language (first, second, and third mover).
} 
The social history available at the end of each period concerns all subjects in the room: the overall number of loans given in the economy and how many of them ended in default; the number of judges that chose to enforce; votes of all lenders and all borrowers; and the average earnings of lenders, borrowers and judges. However, subjects did not observe individual histories and could not therefore develop reputations. More specifically, a subject observed the past actions of economy participants in aggregate form and not the individual histories of the people in her group. Our setting therefore allowed for lender reactions to aggregate behavior of borrowers but precluded the possibility that individual reputations and relational contracts could develop. Contract enforcement thus relied exclusively on anonymous forces and third party enforcers. ${ }^{4}$

The timeline of decisions within a period, which is less critical given the focus of this paper, was the following:

Stage 1. Each lender $(\ell)$ chooses to lend 10 tokens or nothing (save).

Stage 2. Everyone observes the number of loans in the economy but not who received them. Each lender and borrower votes for enforcement or not. Each judge makes a prediction about how many judges will enforce.

Stage 3. Each borrower $(b)$ observes whether she has personally received a loan or not. If the borrower has received a loan, she decides to comply (keep 17 and return 17 tokens) or default (keep 34 and return nothing). In the case of borrower default, each judge $(j)$ decides either to enforce or to accommodate.

Stage 4. Everyone observes the period results, which include individual payoffs, all choices implemented in their own group of three subjects, and the "social history" of their economy.

Participants' main decisions were binary $\{0,1\}$ and we represent them through a set of "I" variables; for instance $I_{\ell 2}=1, I_{b 5}=0, I_{j 3}=1$ denotes that lender 2 gave a loan, borrower 5 defaulted, and judge 3 forced the borrower to pay back. More generally, the first subscript of a variable denotes the role, while the second subscript identifies each of the 5 subjects playing each of the 3 roles, $k=1, \ldots, 5$. Every period, each participant took two decisions at most:

$$
\left(\mathrm{I}_{\ell \mathrm{k}}, \mathrm{V}_{\ell \mathrm{k}}\right),\left(\mathrm{I}_{\mathrm{bk}}, \mathrm{V}_{\mathrm{bk}}\right),\left(\mathrm{I}_{\mathrm{jk}}, \mathrm{G}_{\mathrm{jk}}\right) \text { for } \mathrm{k}=1, \ldots, 5
$$

For lenders and borrowers, the " $V$ " variables represent their vote about enforcement, either 0 or 1. For judges, the " $G$ " variables are the guesses about the number of other judges deciding for enforcement, and can therefore take any integer value between 0 and 4 . For example, when we

\footnotetext{
${ }^{4}$ Litigation costs are set at zero in the experiment. Whatever their importance in the field, we believe these costs are secondary to the purpose of this paper.
} 
observe $V_{\ell 2}=1, V_{b 5}=0, G_{j 3}=3$, this means that lender 2 preferred a generic judge in the economy to enforce; borrower 5 preferred this generic judge to accommodate the borrower's default; and, finally, judge 3 expected 3 of the other 4 judges in that particular economy to have enforced.

The design had a built-in inequality in minimum earnings, which were 50 tokens for lenders, 16 for borrowers, and in-between for judges. This design makes it harder to compare the results with those of previous trust game experiments. However, it offers two major advantages. On the one hand, a variety of motivations - self-interest, inequality aversion, total surplus concernsmake "saving" decisions the worst possible outcome. This intentional inequity aligns the predictions for other-regarding subjects with the predictions for self-regarding subjects. On the other hand, for all motivations it generates an intriguing trade-off between short-term and longterm outcomes, which puts to the test subjects' ability to achieve the best outcome. For instance, inequity-averse borrowers and judges could "default/accommodate" to achieve an outcome with equal earnings. But this outcome is not viable in the long run because lenders are likely to react by "saving," hence generating the most unequal outcome possible. Hence, rational otherregarding borrowers and judges want to give lenders enough profits to induce them to lend. We aim to study how subjects deal with this situation. To make the possibility of ending with the most unequal outcome more vivid, we did not pay the average earnings over the period but earnings in one randomly selected period.

The decision of the judge was elicited with the strategy method: she made a decision every period, but the decision was implemented only when the lender had sent the 10 tokens to the borrower and the borrower had defaulted. In all other cases, her decision was collected but not implemented. 5

Finally, every period we asked lenders and borrowers to vote on what they would like judges to decide. The vote took place after lending decisions but before borrowers' and judges' actions. These votes were labeled opinions in the instructions and might have payoff consequences for lenders and borrowers by influencing judges' enforcement decisions in the constituency treatments. This will become clear later in the paper. Votes were given with reference to one generic judge in the economy, not specifically with reference to the judge matched with each respondent.

\footnotetext{
5 In addition, every period the judge was asked, with no money at stake, to state her beliefs about how many other judges in the session $(0,1,2,3$, or 4$)$ chose to enforce. We did not use this information in the paper.
} 
Treatments. The three treatments differed in the compensation for judges. A common feature in all of them was that judges were paid according to their collective performance, hence in a given period they all earned the same amount.

1) In Lender constituency, judges' payments depended on the agreement between judges' decisions as a group and lenders' votes as a group. More precisely, if the number of judges enforcing was equal to the number of lenders favoring enforcement, judges earned 50 tokens. For every person in disagreement, judges' earnings were lowered by 5 tokens. A judge $k$ earned $\pi_{\mathrm{jk}}=50-5\left|\sum_{\mathrm{x}=1, \ldots, 5} \mathrm{I}_{\mathrm{jx}}-\mathrm{V}_{\ell \mathrm{x}}\right|$, with a minimum of 25 tokens. Borrowers' votes were ignored.

2) In Borrower constituency, judges' payments depended on the agreement between judges' decisions as a group and borrowers' votes as a group. More precisely, if the number of judges enforcing was equal to the number of borrowers also favoring enforcement, judges earned 50 tokens. For every person in disagreement, judges' earnings were lowered by 5 tokens. A judge $k$ earned $\pi_{\mathrm{jk}}=50-5\left|\Sigma_{\mathrm{x}=1, \ldots, 5} \mathrm{I}_{\mathrm{jx}}-\mathrm{V}_{\mathrm{bx}}\right|$, with a minimum of 25 tokens. Lenders' votes were ignored.

3) In GDP, judges earned the average of all lenders and borrowers in the economy. Therefore, what mattered was not just the earnings of the specific lender and borrower matched with that judge but the earnings of all 10 of them in the economy. A judge $k$ earned $\pi_{\mathrm{jk}}=1 / 10 \sum_{\mathrm{x}=1, \ldots, 5}\left(\pi_{\mathrm{ex}}+\pi_{\mathrm{bx}}\right)$, which ranges between 38 and 50 tokens. All votes were ignored.

In addition, we also implemented two variants where some roles were replaced by preprogrammed computers. We refer to those as "Robot Borrower constituency" and "Robot GDP," and will give a full description in section 5 .

We had 189 people participating in the experiment. ${ }^{6}$ Each subject participated in only one of the sessions between February and April 2006 (See Online Appendix A). Recruitment was done at Purdue University mostly in introductory economics classes. A session lasted on average less than two hours, including instruction reading. A participant earned on average \$24, and earnings were paid privately at the end of a session.

\footnotetext{
6 After reading the instructions for the main part, subjects completed a quiz on the rules and those who made the most mistakes were excluded (one out of six). Excluded subjects received $\$ 10$ in addition to their earnings in the initial tasks. Complete instructions are in Online Appendix B.
} 


\section{Theoretical considerations}

Here we will present a theoretical model under the assumption that all agents are risk neutral and will rate economy outcomes according to what we label "surplus," defined as the average payoff of all lenders and borrowers minus their initial endowment of 76 tokens $(60+16)$. This definition of surplus is a partial measure of social efficiency, since judges' earnings are excluded. However, in the field, given that judges are a small minority of agents, this partial surplus should be close to the total surplus. ${ }^{7}$ We will define an economy outcome "low surplus" when all lenders save (zero surplus) and "high surplus" when all lenders lend (surplus of 24). An economy can achieve the socially optimal outcome only when all lenders lend. In the experiment, judges observed the voting of lenders and borrowers at the end of each period, but, to simplify the analysis, the theoretical model in this section assumes that judges observe the voting outcome before making their decisions.

We obtain two propositions, which illustrate that in all treatments there are multiple subgame perfect Nash equilibria.

Proposition 1. In all treatments, there is a low-surplus equilibrium.

We will establish below that there is a low-surplus equilibrium for the one-shot game in each treatment. As a consequence, an equilibrium remains for the repeated game. In the Borrower constituency treatment, borrowers have "control" over third-party enforcers. In a one-shot game suppose all lenders save, the strategy of all borrowers is to default and all vote for accommodating, while all judges rule to accommodate. This strategy profile is a subgame perfect Nash equilibrium, which is supported through a symmetric pure strategy and generates aggregate outcomes $\left(\sum_{k} I_{l k}, \Sigma_{k} V_{\ell k}\right),\left(\Sigma_{k} I_{b k}, \Sigma_{k} V_{b k}\right),\left(\Sigma_{k} I_{j k}\right)=(0,-),(0,0),(0)$, where the terms in parentheses highlight decisions of lenders (number of loans, number of votes for enforcement), borrowers (number of voluntary returns, votes for enforcement), and judges (number of enforcement decisions), respectively. The symbol "-” stands for any choice. Payoffs are $\pi_{\ell}=60$, $\pi_{b}=16$, and $\pi_{j}=50$.

Under GDP, when judges take a decision in a one-shot game, their earnings have already been determined. This is the crucial point, determining that, for any pattern of lenders' and borrowers' decisions, self-regarding judges have no incentive to rule for either enforcement or default. Suppose all lenders save, the strategy of all borrowers is to default and all judges rule to

\footnotetext{
${ }^{7}$ In the GDP treatment, surplus is proportional to the GDP of the economy. In the other two treatments, it is not.
} 
accommodate. This strategy profile is a subgame perfect Nash equilibrium and generates aggregate outcomes ( $0,-)$, (0, -), (0) with payoffs $\pi_{\ell}=60, \pi_{b}=16$, and $\pi_{j}=38$.

Under Lenders constituency, lenders have "control" over third-party enforcers but, in a oneshot game, there is a low-surplus equilibrium because in the experiment judges do not observe the voting outcome until the end of the period. Consider a situation where all lenders save and vote to accommodate. If the strategy of all borrowers is to default and all judges rule to accommodate, we have a strategy profile that is a subgame perfect Nash equilibrium. The aggregate outcomes will be (0,0), (0, -), (0) with payoffs $\pi_{\ell}=60, \pi_{b}=16$, and $\pi_{j}=50.8$

Proposition 2. In all treatments, there is a high-surplus equilibrium.

When the game is repeated indefinitely, new equilibria may appear because subjects consider the effect that their current decisions may have on the future decisions of all subjects. Subjects know that the interaction will continue for sure until period 20. Afterwards, a participant rolls a dice after every period and the session terminates with probability $1 / 6$. Hence, at any point in time, subjects can expect 6 additional periods.

Before showing the high-surplus equilibria for each treatment, note that the best choice for a lender is to lend when her expected payoff is higher than it would be if saving, $E\left[\pi_{\ell k} \mid I_{\ell k}=1\right]>$ $E\left[\pi_{\ell k} \mid I_{\ell k}=0\right]$. This condition is satisfied when the enforcement rate in the economy, $E R$, is more than $E R^{*}=58.82 \% . E R$ is defined as the ratio between the sum of loans returned (both voluntarily by borrowers, $\Sigma_{k} I_{b k}$, or after judicial enforcement, $\left.R_{j}=\Sigma_{k} I_{j k} / 5\right)$ and the sum of loans given, $\Sigma_{\mathrm{k}} \mathrm{I}_{\ell \mathrm{k}}: 9$

$$
\mathrm{ER}=\left[\Sigma_{\mathrm{k}} \mathrm{I}_{\mathrm{bk}}+\left(\sum_{\mathrm{k}} \mathrm{I}_{\ell \mathrm{k}}-\Sigma_{\mathrm{k}} \mathrm{I}_{\mathrm{bk}}\right) \mathrm{R}_{\mathrm{j}}\right] /\left(\sum_{\mathrm{k}} \mathrm{I}_{\mathrm{lk}}\right)
$$

We remain agnostic about how these expectations are generated. In equilibrium, however, expectations should be fulfilled. ${ }^{10}$

\footnotetext{
8 Notice that a design where lenders and borrowers vote, observe the voting outcome, and then choose actions would have reduced the likelihood of ending up in a low-surplus outcome. This alternative design provides a commitment technology where legal promises cannot be reneged either by the citizens or by the State. This technology is rarely available in the field.
}

${ }^{9} \mathrm{We}$ set $\mathrm{I}_{\mathrm{bk}}=0$ for borrowers who do not get to make a choice. Given that this ratio is used by lenders to estimate their return from lending, $I_{l k}$ is at least one and the denominator is always positive. The risk attitude of lenders has a clear impact on the enforcement threshold [6] that is acceptable for giving loans. The more risk averse lenders are, the higher the threshold, $E R^{* *}>E R^{*}$.

10 The Enforcement threshold, ER*, is

$$
\mathrm{E}\left[\pi_{\ell \mathrm{k}} \mid \mathrm{I}_{\ell \mathrm{k}}=1\right]>\mathrm{E}\left[\pi_{\ell \mathrm{k}} \mid \mathrm{I}_{\ell \mathrm{k}}=0\right] \Leftrightarrow 67 \mathrm{E}[\mathrm{ER}]+50(1-\mathrm{E}[\mathrm{ER}])>60 \Leftrightarrow \mathrm{E}[\mathrm{ER}]>\mathrm{E}\left[\mathrm{ER}^{*}\right]=10 / 17 \approx 0.5882
$$

Lending is profitable when more than about $58.82 \%$ of the loans are returned. This enforcement rate can be satisfied with various combinations of borrowers' and judges' choices. For instance, when at least three judges decide to enforce, the threshold is met for any number of voluntary returns. When at least three loans out of five are voluntarily returned, the threshold is met for any judicial ruling (also for 3/4, 2/3 or 1/1). When at least two loans 
In the repeated game under Borrower constituency, borrowers balance the short-run gain they could obtain by leading judges to accommodate, against the long-run losses this accommodation would cause if, as a consequence, lenders were to stop lending in subsequent periods. Suppose all lenders lend in period 1 and keep lending as long as ER $>E R^{*}$ and otherwise save forever. Suppose all borrowers' default and three vote for enforcement while three judges rule for enforcement. This strategy profile is a subgame perfect Nash equilibrium in pure strategies and generates in every period aggregate outcomes (5, -), (0,3), (3) with expected payoffs $E\left[\pi_{\ell}\right]=60.2$, $E\left[\pi_{b}\right]=39.8, \pi_{j}=50$.

If lenders switch from lending to saving in future periods unless they earn a positive period profit in expectation, then borrowers have an incentive to maintain an enforcement level above $E R^{*}$. To illustrate this point, consider that the present value of borrowers' earnings when they vote for $60 \%$ enforcement, i.e., just above $\mathrm{ER}^{*}$, is higher than if (in the current period) they decide to switch to $40 \%$ enforcement:

$$
\begin{gathered}
\sum_{t=0}^{+\infty} \delta^{t} \mathrm{E}\left[\pi_{\mathrm{bk}} \mid \Sigma_{\mathrm{k}} \mathrm{V}_{\mathrm{bk}}=3\right]>\sum_{t=0}^{+\infty} \delta^{t} \mathrm{E}\left[\pi_{\mathrm{bk}} \mid \Sigma_{\mathrm{k}} \mathrm{V}_{\mathrm{bk}}=2\right] \\
{\left[\frac{3}{5} 33+\frac{2}{5} 50\right]+\sum_{t=1}^{+\infty} \delta^{t}\left[\frac{3}{5} 33+\frac{2}{5} 50\right]>50+\sum_{t=1}^{+\infty} \delta^{t} 16}
\end{gathered}
$$

Given that the present value of 1 token received every period in an indefinitely repeated game is $\sum_{t=0}^{+\infty} \delta^{t}=1 /(1-\delta)$, the above inequality holds for a continuation probability of $\delta=5 / 6$. Hence, if only $40 \%$ of borrowers vote to enforce, no borrower would gain.

In the repeated game under GDP, suppose all lenders lend in period 1 and keep lending as long as $E R>E R^{*}$ and otherwise save forever. Suppose all borrowers' default while all judges rule for enforcement. This strategy profile is a subgame perfect Nash equilibrium and generates in every period aggregate outcomes (5, -), (0, -), (5) with expected payoffs $E\left[\pi_{\ell}\right]=67, E\left[\pi_{b}\right]=33$, $\pi_{j}=50$. Nobody gains from unilaterally deviating from this strategy profile. These actions are part of the subgame perfect Nash equilibrium in the repeated game under Lender constituency.

All treatments admit multiple equilibria. Besides Propositions 1 and 2, there is also a range of intermediate-surplus equilibria. Self-regarding subjects prefer to end up in a high-surplus equilibrium rather than in a low-surplus equilibrium whether their role is that of lender or

out of five are voluntarily returned, we need two judges ruling for enforcement, and so on. The enforcement threshold is met $(E R>58.82 \%)$ with four loans when two loans are voluntarily returned and one judge rules for enforcement; with three loans, when one loan is voluntarily returned and two judges rule for enforcement; with two loans, when one loan is voluntarily returned and one judge rules for enforcement. 
borrower. Under GDP, the same holds true for judges, while in the other treatments selfinterested judges are indifferent between low- and high-surplus equilibria.

\section{Main results}

We present the main findings regarding the surplus generated (Result 1) and the distribution of earnings (Result 2). These results are based on the data from interaction periods 11-20, except where otherwise stated. In section 6 we report additional results that allow us explore possible reasons for the main findings (Results 3-6).

Result 1. Economy surplus is remarkably different across treatments. In Lender constituency, subjects reach 100 percent of the potential surplus, and in GDP they reach 69 percent, whereas in Borrower constituency they reach only 10 percent.

Table 1 and Figures 2 and 3 provide support for Result 1. We compute the "economy surplus" subtracting the "economy endowments" (defined as the sum over all groups of the 16 tokens that borrowers receive at the beginning of each period plus the 50 tokens that lenders receive) from the "economy earnings" (defined as the sum of borrowers' and lenders' earnings over all groups). We disregard judges' earnings because they are irrelevant in these two indicators: judges' compensation does not directly affect that of lenders or borrowers. Also note that both total surplus and total earnings are linear in the number of loans made.

Whatever the indicator, the economy's performance differs widely across treatments. In Lender constituency, the economy is at its high-surplus equilibrium where it accrues $100 \%$ of total surplus. In Borrower constituency it is only $10 \%$, close to the low-surplus equilibrium level of $0 \%$, which suggests that subjects coordinated on their least-preferred outcome. In the GDP treatment, subjects manage to achieve $69 \%$ of the potential surplus, which suggests an attempt to coordinate on the high-surplus equilibria. Figure 2 includes the results for the two "robot" variants, which will be described in section 6 .

The difference in the number of loans, which is proportional to the economy surplus, is already weakly significant in period 1 when comparing Borrower constituency and the other treatments (Fisher exact test, two-tailed, $p=0.076, N=45$ ). A panel regression on the number of loans in each period reports a highly significant difference between Borrower constituency and the other treatments pooled together (see the coefficient of the Borrower constituency treatment 
dummy in Table 1). The trend observed in the number of loans makes the contrast between treatments even clearer (also Table 1 and Figure 3).

\section{Result 2. Under Borrower constituency, borrowers make their smallest earnings both} in absolute and relative terms.

Paradoxically, borrowers end up worse off under Borrower constituency — when they hold voting rights that command enforcement - than in the other treatments. When lenders "control" judges, borrowers' earnings are higher in both absolute and relative terms. Borrowers' shares are 24.0\% under Borrower constituency vs. 33.0\% under Lender constituency (Figure 4), and borrowers' absolute earnings are 18.8 vs. 33.0 tokens (Figure 5), respectively. In the GDP treatment, borrowers also fare well, enjoying a marginal increase in their share of earnings (33.2\%) with respect to Lender constituency, but suffering a small decline in their absolute earnings (30.8). Recall that the data reported are averages for interaction periods 11-20.

A panel regression on the share of borrowers' earnings finds a highly significant coefficient for the Borrower constituency dummy (Table 1). ${ }^{11}$ The dynamic is nicely illustrated by Figures 3 and 6. In Lender Constituency, borrowers earn well because of the steady flow of loans, which are routinely repaid and deliver a profit to both lenders and borrowers. In Borrower Constituency, borrowers who got a loan received a high payoff because they generally defaulted but most of the borrowers languished with no loan. Finally, in GDP there is a trend towards increasing the repayment rate, which boosts average lenders' profits and the number of loans. The following sections explore possible explanations for Results 1 and 2.

\section{Experimental design: additional aspects}

At the beginning of each session, we elicited the preferences of all subjects with respect to equality and efficiency in a static context, along the lines of Engelmann and Strobel (2004). We presented two tables to each subject. Each table presented subjects with a choice between alternative allocations of money among three persons (roles 1, 2, and 3). Subjects faced role uncertainty as they made these decisions because roles were assigned randomly at the end of the session. Participants were instructed to choose among the following earning distributions (person

\footnotetext{
11 Treatment differences are also highly significant with respect to absolute borrowers' earnings. In Online Appendix A, Table 2A reports the results of a multinomial regression model run on periods 11-20 and on all periods. The possible earnings levels are 16, 33, or 50 and in Borrower constituency the likelihood of a 16 outcome is significantly higher than in the other treatments.
} 
1, person 2, person 3), $A:(8,8,8), B:(11,8.5,4.5)$, and $C:(12,9,3)$ and then $D:(20.5,6.5,5)$, $E:(12,7,5)$, and $F:(7.5,7.5,5)$ as if they knew they were Person 2. Choices were written on a personal card. When computing earnings, we randomly formed groups and randomly assigned roles. Only the choice of the participant selected as person 2 mattered for deciding her group allocation. The choices of persons 1 and 3 were ignored. Half of the groups were paid according to choices made among A, B, C and the other half to choices D, E, F.

After this task we ran a one-shot guessing game in which all subjects had to write a real number between 0 and 100 on their personal decision cards. They were informed that we would randomly form groups of three, and would then compute a target number for each group by taking two thirds of the group average. Within each group, the subject closest to her target number received 6 points, which were evenly split in cases of ties.

At that point, the experimenter collected all decision cards and wrote the results for both tasks on the cards, which were returned to the subjects at the end of the session.

The best choices for a rational, self-interested agent in the earlier task are $C$ and $F$. In the latter task, the Nash equilibrium is to choose the number 0 . The prize is split equally and individual earnings are 2 points. A detailed report about these tasks is given in Arruñada et al. (2012).

To study issues of coordination and other-regarding motivations, we employed modified treatments where robots replaced humans in some roles (Table 1). With the exception of period 1 , robots followed deterministic rules.

- Robot Borrower constituency is a variation of the Borrower constituency treatment, where borrowers are humans while lenders and judges are robots. Robot lenders will lend whenever they expect a profit. They base profit expectations on the past average enforcement in the economy. Some lender robots consider only decisions made in the last period, while others consider up to four. Coin flips decide Robot lenders' behavior in period one. Robot judges rule in perfect accordance to borrowers' opinions.

- Robot GDP is a variation of the GDP treatment, where judges are humans while lenders and borrowers are robots. Robot lenders are programmed in the same way as in the previous variation. Robot borrowers always default.

The instructions explained that subjects played against robots and the rules were followed by the robots in the same way as described above (Online Appendix B). These robot treatments considerably simplify coordination problems as there were only five human subjects in the 
economy. Moreover, in the robot treatments there was common interest among all subjects, as robots were not actually paid. Importantly, other-regarding participants would ignore robot earnings.

\section{Explaining our main results}

One would like to know why in different treatments subjects selected different equilibria (Results 1 and 2). In particular, one may wonder about the poor performance of Borrower constituency. We will now analyze three conjectures: (a) difficulties in understanding market interactions; (b) other-regarding preferences; and (c) coordination problems on strategies. This analysis will show that other-regarding preferences and coordination problems do not reasonably explain our main results. Conjecture (a) best explains the data by employing a steps-of-reasoning model to capture the difficulties in understanding market interactions.

Result 3. The difficulty of subjects to make multiple steps of reasoning provides a selection criterion to explain a high-surplus outcome in the GDP and Lender constituency treatments and a low-surplus outcome in the Borrower constituency treatment.

We operationalize the cognitive difficulty of each treatment using two variables: (1) the correspondence between the early versus the late effects of the choices made by the key actors; and (2) the number of steps of reasoning that the key actors have to make in order to predict aggregate outcomes - specifically, the number of decisions to be made by other subjects and which the key actors have to predict. According to these two variables, we can rank treatments as follow:

- Lender constituency is an "easy" treatment: (1) lenders are the key actors and get an early benefit from voting for enforcement. Hence there is alignment between the early and late effects of voting for enforcement; and (2) lenders face a simple reasoning: when voting, a lender has to predict how judges will decide.

- GDP is a "moderately difficult" treatment: (1) judges are the key actors and their decisions have only late effects on earnings_-judges' incentives come from lenders' reactions in the following periods. Hence there is a partial misalignment between early and late incentives; and (2) judges face a simple reasoning: when deciding on enforcement, a judge has to predict lenders' reactions. 
- Borrower constituency is a "difficult" treatment: (1) borrowers are the key actors and, in the high-surplus equilibria, face a conflict between early and late effects, as enforcement might imply an early loss but generate a late gain; and (2) borrowers face a more complex chain of reasoning: when voting, a borrower first has to predict how judges will decide and, second, how lenders will react to judges' enforcement decisions.

When agents are sophisticated in terms of steps of reasoning, the above ranking is irrelevant. Our subjects instead are characterized by a limited number of iterations of reasoning, which we measured in the experiment using the guessing game of the preliminary tests. Our classification provides a noisy, though useful, proxy. As reported in Table 3, about $29.7 \%$ of subjects did zero steps of reasoning. When subjects do a limited number of steps of reasoning, we predict that whenever short-run and long-run incentives of the key actors are misaligned, their choices will be closer to their short-run incentives, which is what we observe in the data: empirical evidence at the individual level, provided by the regression results shown in Tables 4 and 5, illustrates that the choices key actors made are broadly linked to cognitive limitations in the number of iterations of reasoning they exhibited in the guessing game.

In the GDP treatment, judges with zero iterations of reasoning should enforce less than other judges. This pattern holds significantly for the robot variants of the GDP treatment if one looks only at those periods where the unilateral deviation of one judge's decision was pivotal for reaching or not reaching the zero-profit enforcement threshold, $E R^{*}$ (column 4 of Table 4).

In the Borrower constituency treatment, borrowers with zero iterations of reasoning voted less frequently for enforcement than other borrowers. This result is weakly significant in the human variant and highly significant in the robot variant (Table 5). Moreover, in contrast with the GDP treatment, in the Borrower constituency treatment there is no evidence of adjustment over time. Although based on a small sample size, these regressions exhibit an overall pattern that points toward the difficulty subjects have in understanding the systemic consequences of their choices within a market mechanism. This behavior may be related to the failure to backward induct, which has been documented, among others, by McKelvey et al. (1992) and Palacios-Huerta and Volij (2009). Depending on the institutional arrangement, some of the outcomes in the equilibrium set were easier for subjects to achieve than others.

Alternative conjectures (b) and (c) are presented below in Results 4 and 5. Overall, they do not provide a satisfactory explanation for the main results. We observe that subjects willing to pay for perfect equality or for highest total surplus in the preliminary tests were significantly less 
likely to vote for enforcement in Borrower constituency (Table 5). This evidence could point toward social preferences as the driver of the borrowers' paradox. ${ }^{12}$ A myopic application of other-regarding concerns to the immediate situation obscures the long-term consequences of current decisions. However, although this "hot" vs. "cold" application of other-regarding preferences might play a role, it turns out to be a second-order factor, as we will see in Result 4 .

Result 4. When some roles are replaced by pre-programmed robots, the differences between Borrower constituency and GDP treatments remain equally strong.

Support for Result 4 comes from Figures 2-5 and Tables 4-5. The data do not support conjecture (b) about the main results being driven by other-regarding preferences, because those motivations are removed in the absence of human counterparts. However, in these "robot" treatments we still observe the paradox in borrowers' absolute and relative earnings reported in the main treatments (Figures 4 and 5). The comparative static in terms of economy surplus between Borrower constituency and GDP yields a distance of 59 percentage points for the human treatments vs. 57 percentage points in the robot treatments, which are very similar as to what was reported for Result 1 . The distance in terms of the share of economy earnings for borrowers is 9 (human) vs. 7 (robot) percentage points, which are also very similar to what was reported for Result 2. Borrowers in Robot Borrower constituency could have imitated the enforcement strategy followed by judges in GDP to achieve higher payoffs, but they did not. ${ }^{13}$ In sum, otherregarding preferences did not drive the differences across treatments in terms of economy surplus and distribution of economy earnings.

An additional explanation is needed. In Borrower constituency, economy surplus increased from $10 \%$ (half a loan in a total of five loans) in the human variation to $40 \%$ (two out of five) in the robot variation (Figure 2). The main reason for this increase in absolute levels lies in our choice of backward-looking robot lenders, which allowed borrowers to sustain a pattern of cycles of enforcement/lending switching into no enforcement/no lending and back to enforcement/lending throughout a session. Because of their design, robot lenders could be fooled throughout a whole session, while even the most optimistic human lenders seem to have

\footnotetext{
12 No significant effect was detected for strongly other-regarding judges in GDP (Table 4).

13 Specific other-regarding preferences cannot explain the results either. If subjects care only about the 50/50 outcome, Borrower constituency still fares badly in comparison to GDP (an average of 0.33 loans per period versus 0.9). If borrowers are spiteful toward lenders, that could explain the results only when assuming an unrealistically high level of spite, because in the steady state a borrower must pay 17 tokens to lower a lender's earnings by 7 tokens. Evidence from other experiments (Casari and Plott, 2003) suggests that spite does not reach the degree required to take such action.
} 
understood the strategy after one or two cycles, and completely stopped giving loans. As a consequence, while economy surplus was stable over time with robot lenders, it steadily declined with human lenders.

As conjecture (b) is not supported by the data, we turn to conjecture (c). Given the multiplicity of equilibria, subjects may coordinate their choices poorly. We identify an "alpha" and a "beta" coordination issue. Subjects' choices might be badly coordinated with other subjects playing the same role, a failure that may affect borrowers' voting in Borrower constituency and judges' enforcement choices in GDP (alpha coordination). Result 5 addresses this issue. Moreover, within the Borrower and Lender constituency treatments, judges might suffer a coordination failure in enforcement choices while matching the voting behavior (beta coordination). Result 6 addresses this issue.

\section{Result 5. When some roles are replaced by pre-programmed robots, subjects readily} solve any coordination issue.

In the two robot variants beta coordination was not an issue and results suggest that subjects successfully solved the alpha coordination issue. In the robot GDP sessions, judges learn to coordinate on a high-surplus equilibrium. Their task is comparable to the one in the GDP variant with all human subjects. In the Robot Borrower constituency, although borrowers may appear erratic, they are actually coordinating on a more sophisticated pattern of cycles. In particular, borrowers behave anti-cyclically toward robot lenders. When robot lenders have given many loans, borrowers vote less frequently for enforcement. ${ }^{14}$ Eventually the loans dry up, borrowers increasingly vote for enforcement again, and then robot lenders start giving loans once more. We now turn to beta coordination issues.

Result 6. Our judges responded well to the incentives provided by the institutional setup, increasing over time the enforcement level in the GDP treatment and ruling close to the voting of the relevant constituency in each of the constituency treatments.

Support for Result 6 is shown in Table 2. The judges in our experiment decide very differently in each of the three treatments, adapting rather well to the different incentives given by each of them. First, under GDP, judges perform poorly in the first periods (they enforce on

\footnotetext{
14 The correlation coefficients between number of loans and borrowers' opinions in the same period are -0.29 in Borrower constituency and -0.44 in Robot Borrower constituency. Borrowers know the number of loans given in the period before stating their opinion about enforcement.
} 
average $49.3 \%$ in periods $1-10$ ) but learn to enforce transactions over time (the rate of enforcement increases to $69.3 \%$ in periods $11-20$ ), sustaining exchanges and increasing the earnings of all participants. Second, under Borrower and Lender constituencies, on average judges rule closely following the opinions of their constituency. ${ }^{15}$ The transmission is perfect in Lender constituency (i.e., judges always enforce), and is close in Borrower constituency, with averages of 1.5 borrowers voting for enforcement and 1.87 judges ruling for enforcement. This discrepancy would bias results in favor of the high-surplus equilibrium and hence judges in Borrower constituency cannot be blamed for the low-surplus results.

In summary, the best explanation for the main results is conjecture (a), which concerns participants' difficulties for understanding market interactions.

\section{Discussion and conclusions}

The story that inspired our experiment was a credit market with two transacting parties and a third-party enforcer. In a sequence of random encounters among anonymous traders playing always the same role, a series of transactions take place between lenders and borrowers. Each transaction realized generates a surplus - hence increases efficiency in the economy - and can change income distribution. If no transaction takes place, by design a lender earns more than three times as much as a borrower. If a transaction takes place, inequality is reduced. In particular, after repayment, a borrower holds about half the wealth of a lender; after a default, instead, a borrower earns the same as a lender because he also keeps the principal. When a borrower defaults, the judge (third party) can either force the borrower to repay the loan or accommodate the default. The best way to ensure both a high surplus and to reduce inequality in the experimental economy is to guarantee a sufficiently high enforcement rate. Without it, lenders will refuse loans in future periods. By design, perfect equality is not a sustainable option but, in equilibrium, borrowers' income share could reach almost $40 \%$ of the total earnings of borrowers and lenders'.

By removing many real-world details that might confound our findings, this experiment allows us to focus on the enforcement of impersonal trade. In the experiment, we obtain that the market for loans tends to disappear when judges do not enforce. But this risk of enforcement failure is ever present also in the field, with judges potentially accommodating contractual

\footnotetext{
15 Furthermore, adjustment over time seems to happen faster than in the GDP treatment.
} 
default or, generally, States failing to enforce obligations, as exemplified by the difficulties often observed in mortgage markets. ${ }^{16}$

Given this risk of enforcement failure and its thwarting effect on markets, societies adopt institutions limiting the discretion of enforcers. Judges are generally restrained by judicial precedents and the possibility of appeals, legislators are bounded by constitutional rules, and more specific arrangements also constrain both judges and legislators. For example, judges may be elected or appointed, and their careers may depend on seniority or on merit assessments. Similarly, different political structures - for instance, allocations of voting rights, from limited to universal suffrage - motivate legislators differently.

In the experiment, even if judges enjoy full discretion, as they are always free to enforce repayment or not, they decide under three different institutional arrangements or compensation treatments: in Lender constituency, judges are paid according to lenders' average voting on enforcement; in Borrower constituency, according to borrowers' average voting; and in GDP, according to the earnings of all lenders and borrowers in the economy. The key actors in each treatment - those to whom we allocate enforcement rights - are therefore lenders, borrowers, and judges, respectively.

Some of these institutions failed to produce enforcement and thus made socially-beneficial impersonal exchange impossible while others made it flourish. We argue that this variability was caused by the difficulty of the cognitive problem defined by each set of institutions. In some treatments enforcement rights belonged to lenders, in others to borrowers and in others to judges. The different role as parties to a credit transaction made it more or less difficult to understand the systemic consequences of enforcement. In Lender Constituency, the key actors faced an "easy" problem with respect to enforcement and were successful in supporting welfareimproving transactions. On the contrary, in Borrower Constituency the market disappeared because the key actors faced a more serious problem with respect to enforcement, and this happened even when these parties would have benefitted from sustaining transactions.

The results are striking because all our decision makers, including borrowers, had incentives to enforce. In other words, all had an interest in extending the market. We can therefore conclude that in our set-up incentives are not an exhaustive criterion for designing market-enforcing institutions. The key actors must also face a task they can handle easily. Consequently, the

\footnotetext{
16 Given the reality of incomplete contracts, judges do not merely compel parties to comply with their predefined obligations but also define their obligations in unforeseen contingencies; and this double task makes it possible for them to disguise enforcement failures as contractual "completions". Moreover, the State, as a sovereign actor, is in a position of power over contractual parties.
} 
functioning of an impersonal market is fragile because some institutions pose problems that are too difficult for agents, and their poor understanding of the systemic consequences of their decisions leads to enforcement failures that destroy exchange opportunities. ${ }^{17}$

From a broader perspective, enforcement depends on political structures. It is tempting to establish parallels between our treatments and different allocations of voting and enforcement rights in the field. At their most general, our treatments might be suggestive of different forms of democracy, in which the third-party enforcers (either the government or the judiciary, or both) are directly controlled by different social groups. Our results could thus contribute to the literature on the links between democracy, the rule of law, and growth (Barro, 1996). They also hint that certain forms of education might promote growth by alleviating the enforcement problem.

However, when extrapolating from the experiment, one must keep in mind the implicit set of assumptions about reality embedded in the specificities of the experimental design. In particular, our design of Borrower constituency could resemble a malfunctioning democracy, but future work may reveal that the poor performance of Borrower constituency is reversed by allowing communication, or by having borrowers vote before lenders decide to lend or not, or by letting borrowers implement some commitment device. On the contrary, our results could be reinforced if the experimental borrowers made decisions affecting not their future loans but those of other borrowers in the market, as is most often the case in the field.

Our GDP treatment can itself be interpreted as a commitment device because experimental voters cannot change the role and compensation of enforcers. It therefore resembles societies with effective separation of powers, especially those with (1) an independent judiciary where judges' careers are uncoupled from the short-term desires of their constituencies; and (2) voters who are quite responsive to economic performance. In the field, however, both of these institutions show varying performance, and this diversity might also arise in the experiment if judges' compensation were modified to resemble fixed judicial salaries or short-term political horizons.

Last, our design of Lender constituency apparently resembles an elitist democracy or an oligarchy of the sort prevalent in the $19^{\text {th }}$ century or more recently in some Asian countries. It is left for future work to determine, however, the extent to which outcomes of the Lender constituency treatment depend on our implicit assumptions about enforcement. Our experimental

17 We know incentives are also important for judges. In the 1930s, US states suffering the most severe farm distress were more likely to enact mortgage moratoria. Similarly, elected US judges tend to rule in favor of local businesses (Tabarrok and Helland, 1999). 
subjects enjoy decision rights on the enforcement of contracts but cannot modify the endowments, because we implicitly assume perfect and cost-free enforcement of property rights (that is, endowments are not expropriable by political action). Were we to introduce more consistent assumptions about imperfect enforcement of both contractual and property rights, one may conjecture a tradeoff between both imperfections, making Borrower constituency more effective and Lender constituency less effective than under our assumptions. 


\section{References}

Alston, Lee J. "Farm Foreclosure Moratorium Legislation: A Lesson from the Past." American Economic Review, 1984, 74(3), 445-457.

Arruñada, Benito, Casari, Marco, and Pancotto, Francesca. "Pro-sociality and Strategic Reasoning in Economic Decisions," Frontiers in Behavioral Neuroscience, 2015, 9(140).

Berg, Joyce, Dickhaut, John and McCabe, Kevin. "Trust, Reciprocity, and Social History," Games and Economic Behavior, 1995, 10(1), 122-42.

Barro, Robert J. "Democracy and Growth,” Journal of Economic Growth, 1996, 1(1), 1-27

Bohnet, Iris, Frey, Bruno S. and Huck, Steffen. "More Order with Less Law: On Contract Enforcement, Trust and Crowding." American Political Science Review, 2001, 95(1), 13144.

Brown, Martin, and Christian Zehnder. "Credit Reporting, Relationship Banking, and Loan Repayment," Journal of Money, Credit and Banking, 2007, 39(8), 1883-918.

Camerer, Colin F. Behavioral Game Theory: Experiments in Strategic Interaction, Princeton: Princeton University Press, 2003

Casari, Marco, and Plott, Charles R. "Decentralized Management of Common Property Resources: Experiments with a Centuries-Old Institution," Journal of Economic Behavior \& Organization, 2003, 51, 2, 217-47.

de Soto, Hernando. The Mystery of Capital: Why Capitalism Triumphs in the West and Fails Everywhere Else. New York: Basic Books, 2000.

Engelmann, Dirk, and Strobel, Martin. "Inequality Aversion, Efficiency, and Maximin Preferences in Simple Distribution Experiments." American Economic Review, 2004, 94(4), 857-69.

Fehr, Ernst, and Zehnder, Christian. 2009. "Reputation and Credit Market Formation: How Relational Incentives and Legal Contract Enforcement Interact.” IZA Discussion Papers 4351, Institute for the Study of Labor (IZA).

Field, Erica and Torero, Maximo. "Do Property Titles Increase Credit Access Among the Urban Poor? Evidence from a Nationwide Titling Program." Harvard University Department of Economics, mimeo, March 2006.

Galiani, Sebastian, and Schargrodsky, Ernesto. "Property Rights for the Poor: Effects of Land Titling." Journal of Public Economics, 2010, 94(9-10), 700-29.

Granovetter, Mark. "Economic Action and Social Structure: The Problem of Embeddedness." American Journal of Sociology, 1985, 91(3), 481-510. 
Guthrie, Chris, Rachlinski, Jeffrey J. and Wistrich, Andrew J. "Inside the Judicial Mind." Cornell Law Review, 2001, 86(4), 777-830.

Johnson, Simon, and John McMillan. "Courts and Relational Contracts." Journal of Law, Economics and Organization, 2002, 18, 1, 221-77.

McKelvey, Richard D., and Palfrey, Thomas R. "An Experimental Study of the Centipede Game." Econometrica, 1992, 60(4), 803-36.

McNeil, Barbara J., Pauker, Stephen G., Sox, Harold C., and Tversky, Amos. "On the Elicitation of Preferences for Alternative Therapies." New England Journal of Medicine, 1982, 306(21), 1259-62.

North, Douglass C. Institutions, Institutional Change and Economic Performance, Cambridge: Cambridge University Press, 1990.

North, Douglass C., and Thomas, Robert Paul. The Rise of the Western World: A New Economic History, Cambridge: Cambridge University Press, 1973.

Palacios-Huerta, Ignacio, and Oscar Volij. "Field Centipedes," American Economic Review, 2009, 99(4), 1619-35.

Seabright, Paul. The Company of Strangers: A Natural History of Economic Life, Princeton and Oxford: Princeton University Press, 2004.

Tabarrok, Alexander, and Helland, Eric. "Court Politics: The Political Economy of Tort Awards." Journal of Law and Economics, 1999, 42(1), 157-88.

Westen, Drew, Blagov, Pavel S., Harenski, Keith, Kilts, Clint, and Hamann, Stephan. "Neural Bases of Motivated Reasoning: An fMRI Study of Emotional Constraints on Partisan Political Judgment in the 2004 U.S. Presidential Election." Journal of Cognitive Neuroscience, 2006, 18(11), 1947-58. 
Table 1. Tobit regressions about treatment differences

\begin{tabular}{|c|c|c|c|c|}
\hline & \multicolumn{2}{|c|}{$\begin{array}{l}\text { Dependent variable: } \\
\text { Number of loans }\end{array}$} & \multicolumn{2}{|c|}{$\begin{array}{l}\text { Dependent variable: } \\
\text { Borrowers' share of earnings }\end{array}$} \\
\hline & Periods 11-20 & All periods & Periods 11-20 & All periods \\
\hline $\begin{array}{l}\text { Borrower constituency } \\
\text { treatment }\end{array}$ & $\begin{array}{l}-5.319 \\
(1.354)^{* * *}\end{array}$ & $\begin{array}{l}-5.854 \\
(1.198)^{* * *}\end{array}$ & $\begin{array}{l}-0.107 \\
(0.015)^{* * *}\end{array}$ & $\begin{array}{l}-0.122 \\
(0.014)^{* * *}\end{array}$ \\
\hline $\begin{array}{l}(1 / \text { period }) * \text { Borrower } \\
\text { constituency }\end{array}$ & & $\begin{array}{l}6.111 \\
(2.054)^{* * *}\end{array}$ & & $\begin{array}{l}0.108 \\
(0.030)^{* * *}\end{array}$ \\
\hline $1 /$ period & & $\begin{array}{l}-2.053 \\
(1.736)\end{array}$ & & $\begin{array}{l}0.048 \\
(0.024)^{* *}\end{array}$ \\
\hline Constant & $\begin{array}{l}4.716 \\
(0.995)^{* * *}\end{array}$ & $\begin{array}{l}4.906 \\
(0.991)^{* * *}\end{array}$ & $\begin{array}{l}0.331 \\
(0.004)^{* * *}\end{array}$ & $\begin{array}{l}0.329 \\
(0.004)^{* * *}\end{array}$ \\
\hline No. observations & 90 & 246 & 90 & 246 \\
\hline
\end{tabular}

Notes: An observation is the average value in a period of a session. Loans are in the $[0,5]$ interval and share of earnings in the $[0.21053,0.5]$ interval. Three treatments included, no robot treatments. Random effects model. Standard errors in parentheses, ${ }^{*}$ significant at $10 \% ;{ }^{* *}$ significant at $5 \% ;{ }^{* * *}$ significant at $1 \%$. 
Table 2. Enforcement

\begin{tabular}{|c|c|c|c|c|}
\hline$D F$ & $\begin{array}{l}\text { Borrower } \\
\text { constituency }\end{array}$ & $\begin{array}{l}\text { Lender } \\
\text { constituency }\end{array}$ & $\begin{array}{c}\text { Robot } \\
\text { GDP }\end{array}$ & $\begin{array}{c}\text { Robot } \\
\text { Borrower } \\
\text { constituency }\end{array}$ \\
\hline
\end{tabular}

Enforcement rate, both

voluntary and judicial (periods 11-

20 only $)^{\dagger}$

$69.3 \%$

$37.0 \%$

$100.0 \%$

$73.9 \%$

$36.6 \%$

Voluntary compliance by

borrowers (periods 11-20 only)

$13.7 \%$

$13.3 \%$

$11.0 \%$

$0.0 \%$

$23.2 \%$

Judges' enforcement and lenders'

and borrowers' voting

\begin{tabular}{lllllc} 
Judges enforcing & 3.10 & 1.87 & 5.00 & 3.73 & 1.93 \\
Lenders voting for enforcement & 4.43 & 3.27 & $5.00^{*}$ & $\mathrm{n} / \mathrm{a}$ & $\mathrm{n} / \mathrm{a}$ \\
Borrowers voting for enforcement & 0.85 & $1.50^{*}$ & 0.70 & $\mathrm{n} / \mathrm{a}$ & 1.93 \\
$\begin{array}{l}\text { Equal borrower/lender outcome } \\
\text { periods 11-20 only) }\end{array}$ & 0.90 & 0.33 & 0.00 & 1.23 & 1.17 \\
\hline
\end{tabular}

Notes: ${ }^{\dagger}$ The lender zero-profit threshold is $E R^{*}=58.8 \% .{ }^{*}$ Votes had payoff consequences for judges.

Average number of 50/50 split earnings per period. 
Table 3. Guessing game

\begin{tabular}{llcc}
\hline $\begin{array}{c}\text { Iterations of } \\
\text { reasoning }\end{array}$ & $\begin{array}{c}\text { Choice in the } \\
\text { guessing game }\end{array}$ & $\begin{array}{c}\text { Number of } \\
\text { subjects }\end{array}$ & $\%$ \\
\hline 0 & {$[50,100]$} & 49 & $29.7 \%$ \\
1 & $(33.33,50]$ & 50 & $30.3 \%$ \\
2 & $(22.22,33.33]$ & 36 & $21.8 \%$ \\
3 or more & {$[0,22.22]$} & 30 & $18.2 \%$ \\
\hline Totals & {$[0,100]$} & 165 & $100 \%$ \\
\hline
\end{tabular}

Notes: The winning number was the closest to a target equal to $2 / 3$ of the average of three guesses between 0 and 100. The Nash equilibrium was zero. The average guess was 39.90. All participants were included. 
Table 4. Judges' decisions in the GDP treatment

(Dependent variable: $1=$ judge ruled for enforcement, $0=$ otherwise)

\begin{tabular}{|c|c|c|c|c|}
\hline \multirow[b]{2}{*}{$\begin{array}{l}\text { Independent } \\
\text { variables: }\end{array}$} & \multicolumn{2}{|c|}{$\begin{array}{l}\text { With humans as } \\
\text { lenders and judges }\end{array}$} & \multicolumn{2}{|c|}{$\begin{array}{c}\text { With robots as } \\
\text { lenders and borrowers }\end{array}$} \\
\hline & $\begin{array}{l}\text { All } \\
\text { periods } \\
\text { (1) }\end{array}$ & $\begin{array}{c}\text { Pivotal periods } \\
\text { only } \\
\text { (2) }\end{array}$ & $\begin{array}{l}\text { All } \\
\text { periods } \\
\text { (3) }\end{array}$ & $\begin{array}{l}\text { Pivotal periods } \\
\text { only } \\
\text { (4) }\end{array}$ \\
\hline $\begin{array}{l}\text { Voluntary return rate in } \\
\text { previous period }\end{array}$ & $\begin{array}{l}-0.008 \\
(0.233)\end{array}$ & - & - & - \\
\hline Zero iterations of reasoning & $\begin{array}{l}-0.109 \\
(0.246)\end{array}$ & $\begin{array}{l}0.214 \\
(0.205)\end{array}$ & $\begin{array}{l}-0.185 \\
(0.205)\end{array}$ & $\begin{array}{l}-0.515 \\
(0.196)^{* * *}\end{array}$ \\
\hline Strictly self-regarding & $\begin{array}{l}0.101 \\
(0.168)\end{array}$ & $\begin{array}{l}-0.005 \\
(0.193)\end{array}$ & - & - \\
\hline Strongly other-regarding & $\begin{array}{l}0.086 \\
(0.202)\end{array}$ & $\begin{array}{l}-0.229 \\
(0.260)\end{array}$ & - & - \\
\hline $1 /$ period & $\begin{array}{l}-0.991 \\
(0.364)^{* * *}\end{array}$ & $\begin{array}{l}-0.120 \\
(0.208)\end{array}$ & $\begin{array}{l}-0.282 \\
(0.047)^{* * *}\end{array}$ & $\begin{array}{l}0.162 \\
(0.262)\end{array}$ \\
\hline No. obs. & 460 & 210 & 390 & 180 \\
\hline No. subjects & 20 & 20 & 15 & 15 \\
\hline
\end{tabular}

Notes: Marginal effects estimated from probit regressions with random effects. Pivotal periods are those in which the unilateral deviation of one judge's decision was pivotal for reaching or not reaching the zero-profit enforcement threshold, $E R^{*}$. Each subject was coded through three dummy variables using choices in the preliminary tests: zero iteration of reasoning, strictly self-regarding, strongly other-regarding. The latter dummy equals 1 when a subject chose A and D. Period 1 excluded in (1) and (3) because of the lag regressor. ${ }^{*}$ Significant at $10 \%$; ${ }^{* *}$ significant at $5 \% ;{ }^{* * *}$ significant at $1 \%$. 
Table 5. Borrowers' voting in Borrower constituency

(Dependent variable: $1=$ borrower voted for enforcement, $0=$ otherwise)

\begin{tabular}{|c|c|c|c|c|}
\hline \multirow[b]{2}{*}{$\begin{array}{l}\text { Independent } \\
\text { variables: }\end{array}$} & \multicolumn{2}{|c|}{$\begin{array}{l}\text { With humans as } \\
\text { lenders and judges }\end{array}$} & \multicolumn{2}{|c|}{$\begin{array}{l}\text { With robots as } \\
\text { lenders and judges }\end{array}$} \\
\hline & $\begin{array}{l}\text { All } \\
\text { periods } \\
\text { (1) }\end{array}$ & $\begin{array}{c}\text { Pivotal periods } \\
\text { only } \\
\text { (2) }\end{array}$ & $\begin{array}{l}\text { All } \\
\text { periods } \\
\text { (3) }\end{array}$ & $\begin{array}{c}\text { Pivotal periods } \\
\text { only } \\
\text { (4) }\end{array}$ \\
\hline $\begin{array}{l}\text { Voluntary return rate } \\
\text { in previous period }\end{array}$ & $\begin{array}{l}-0.108 \\
(0.038)^{* * *}\end{array}$ & - & $\begin{array}{l}-0.018 \\
(0.247)\end{array}$ & - \\
\hline Zero iterations of reasoning & $\begin{array}{l}-0.119 \\
(0.062)^{*}\end{array}$ & $\S$ & $\begin{array}{l}-0.287 \\
(0.089)^{* * *}\end{array}$ & $\begin{array}{l}-0.425 \\
(0.077)^{* * *}\end{array}$ \\
\hline Strictly self-regarding & $\begin{array}{l}-0.020 \\
(0.062)\end{array}$ & $\begin{array}{l}-0.011 \\
(0.039)\end{array}$ & - & - \\
\hline Strongly other-regarding & $\begin{array}{l}-0.176 \\
(0.037)^{* * *}\end{array}$ & $\begin{array}{l}-0.225 \\
(0.049)^{* * *}\end{array}$ & - & - \\
\hline $1 /$ period & $\begin{array}{l}0.032 \\
(0.484)\end{array}$ & $\begin{array}{l}-0.048 \\
(0.279)\end{array}$ & $\begin{array}{l}0.389 \\
(0.248)\end{array}$ & $\begin{array}{l}0.628 \\
(0.470)\end{array}$ \\
\hline No. obs. & 405 & 148 & 380 & 190 \\
\hline No. subjects & 15 & 15 & 15 & 15 \\
\hline
\end{tabular}

Notes: Marginal effects estimated from probit regressions with random effects. Pivotal periods are those in which each borrower's decision was pivotal for reaching or not reaching the zero-profit enforcement threshold, $E R^{*}$. Regressor was dropped because it perfectly predicted ruling against enforcement (structural zeroes). Period 1 excluded in (1) and (3) because of the lag regressor. ${ }^{*}$ Significant at $10 \% ;{ }^{* *}$ significant at $5 \%$; ${ }^{* * *}$ significant at $1 \%$. 
Figure 1. Modified trust game

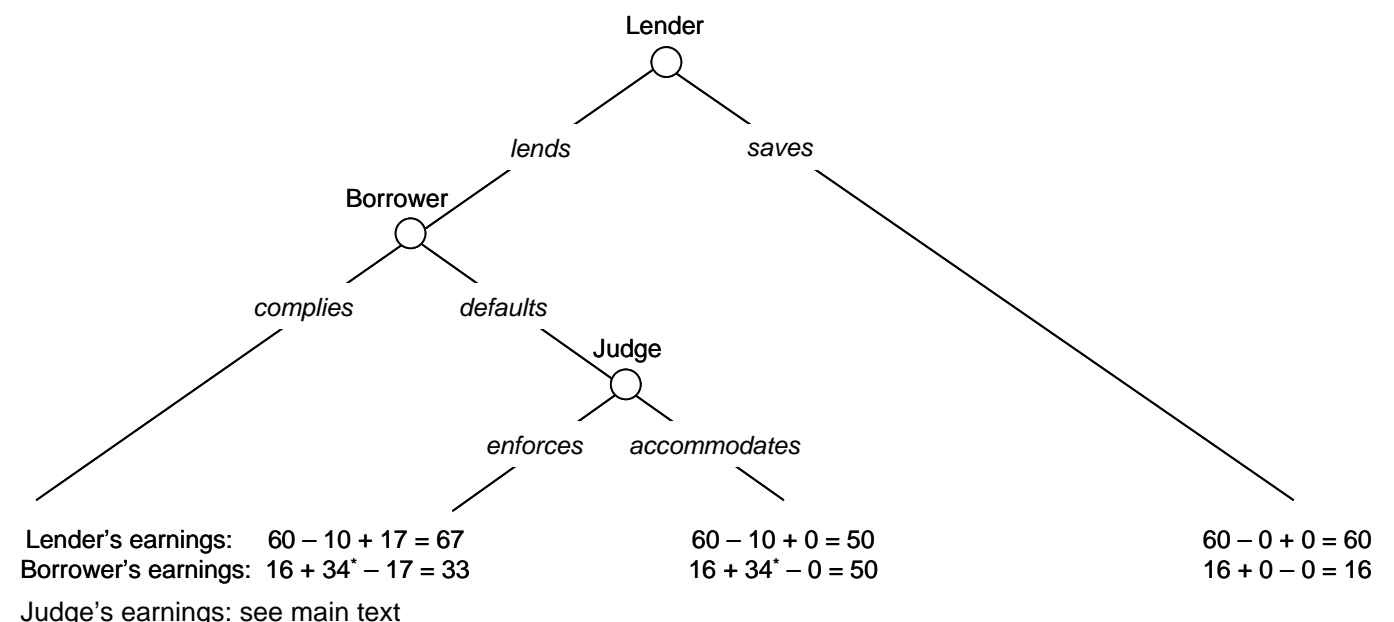

Notes: An experimental token was worth USD 0.45 . There were no practice periods. 
Figure 2. Average number of loans by treatment

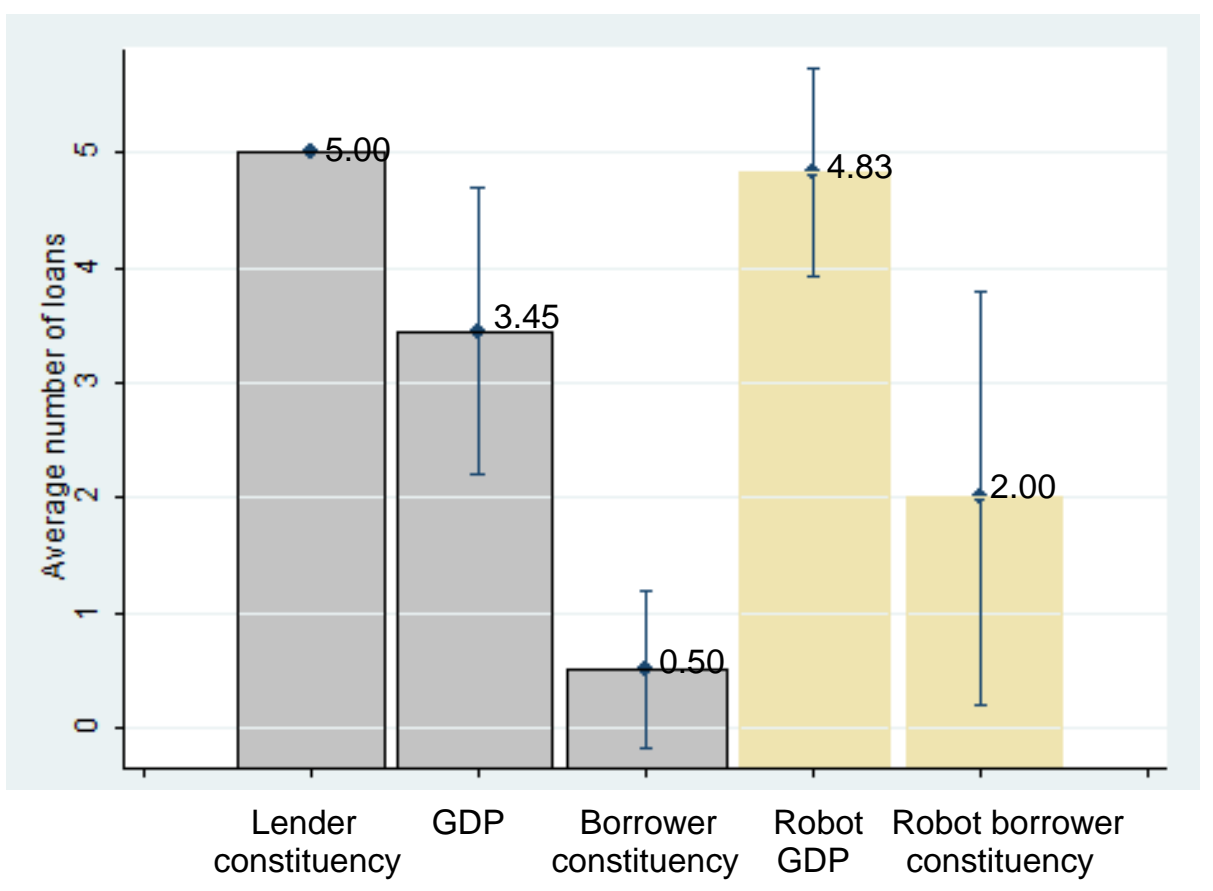

Notes: Periods 11-20 only. Aggregate surplus is zero with zero loans and reaches its full potential with five loans. Bars indicate standard deviations on period averages. 
Figure 3. Number of loans over time in the economy

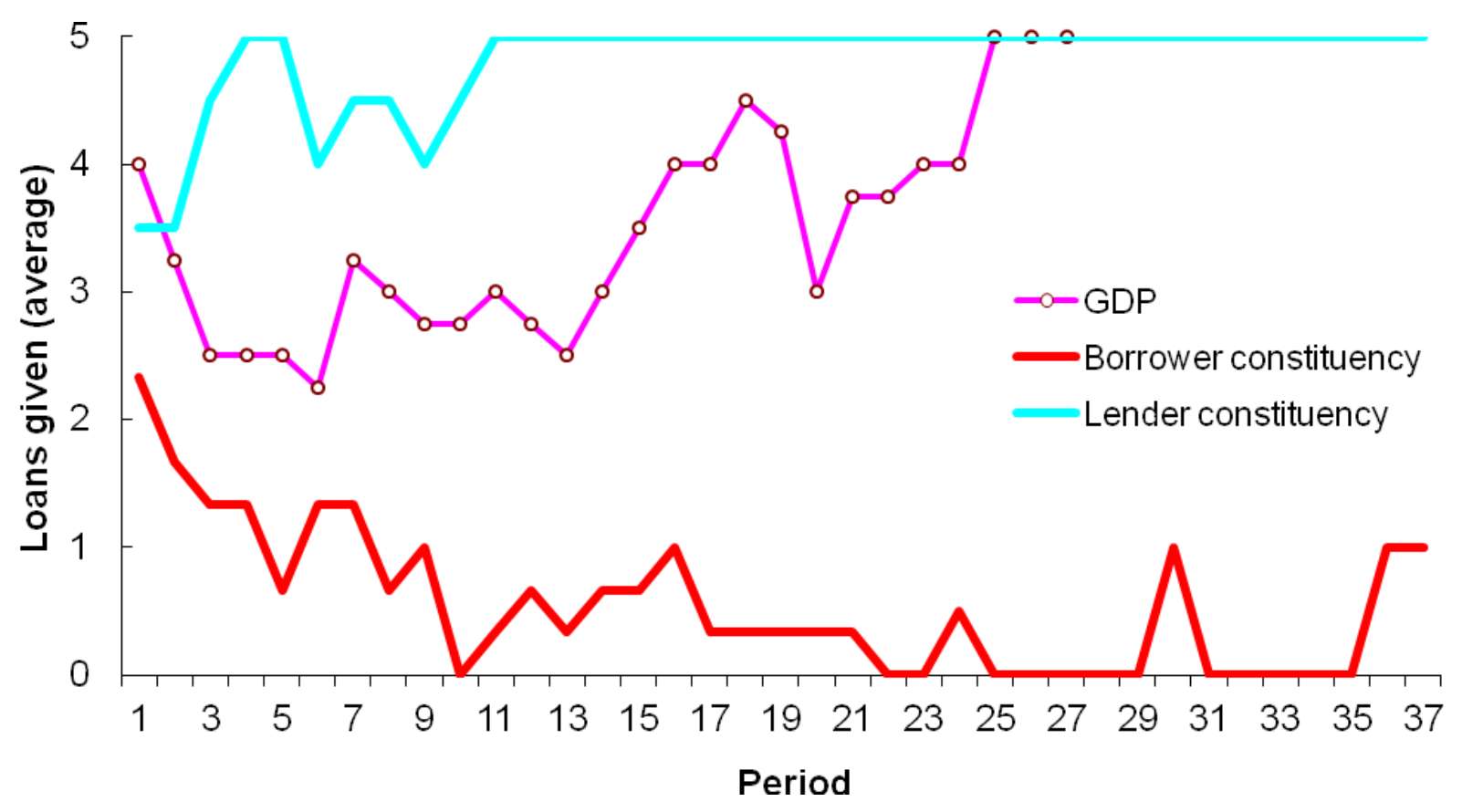

Note: Shortest session: 22 periods, longest session: 37 periods. 
Figure 4. Borrowers' share of total earnings

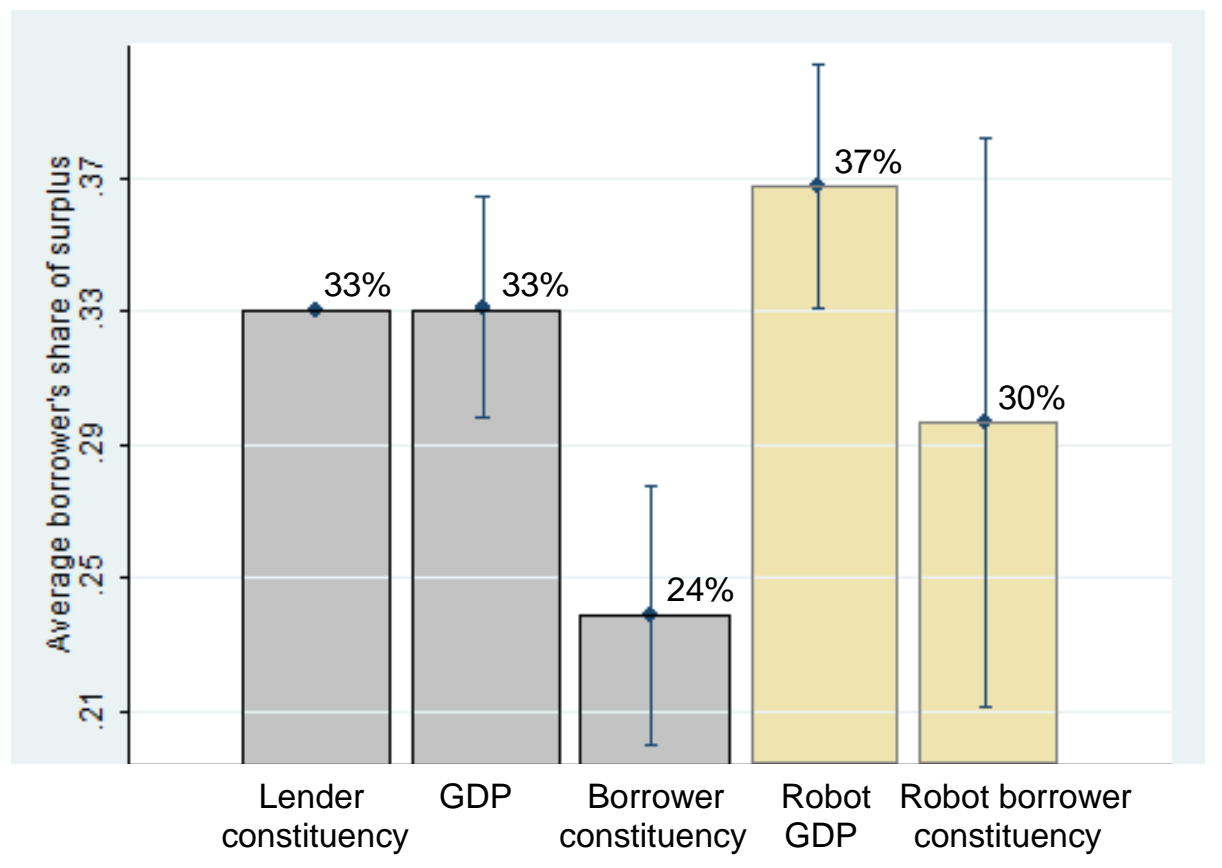

Note: Periods 11-20 only. Borrowers' share on the sum of borrowers' and lenders' earnings. Borrowers can never earn more than $50 \%$ of total earnings and, in equilibrium, up to $39.8 \%$ with risk-neutral lenders. Bars indicate standard deviations on period averages. 
Figure 5. Absolute earnings of borrowers

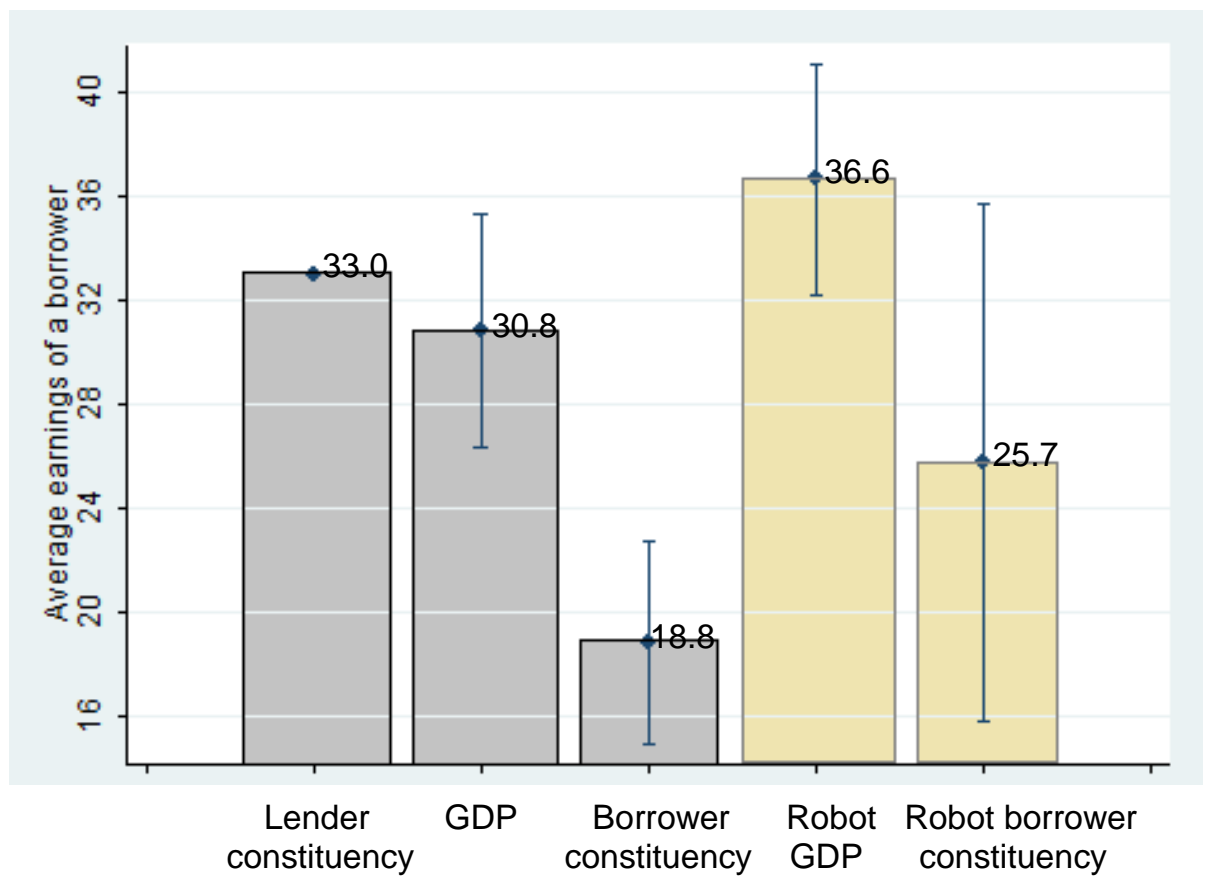

Note: Periods 11-20 only. A borrower has a period endowment of 16 tokens. Borrowers can never earn more than 50 tokens and, in equilibrium, up to 39.8 tokens with risk-neutral lenders. Bars indicate standard deviations on period averages. 
Figure 6.

(A) Lenders' average earnings

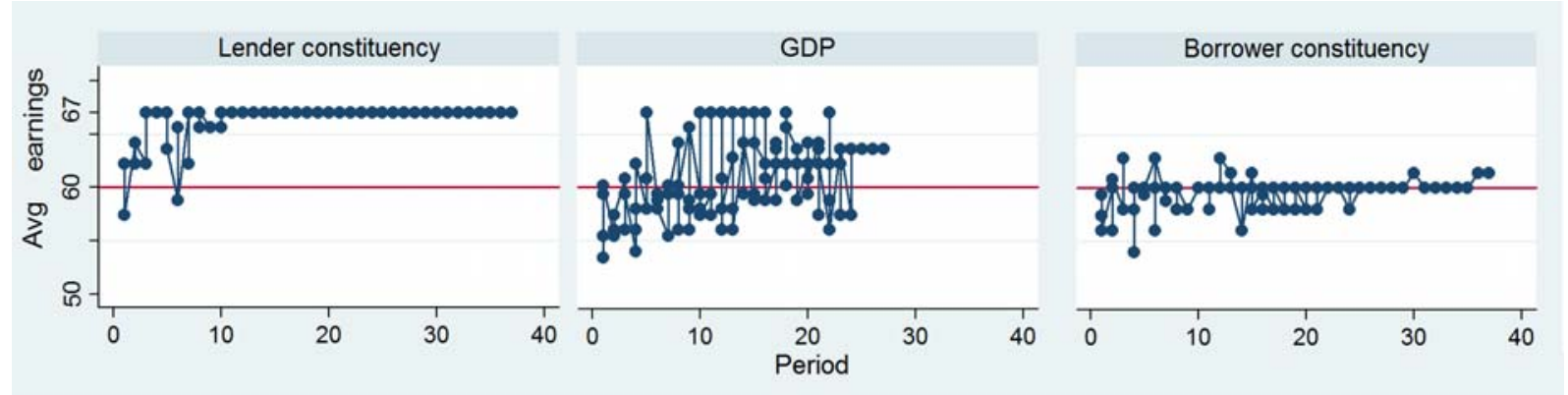

(B) Average earnings of borrowers who actually received a loan

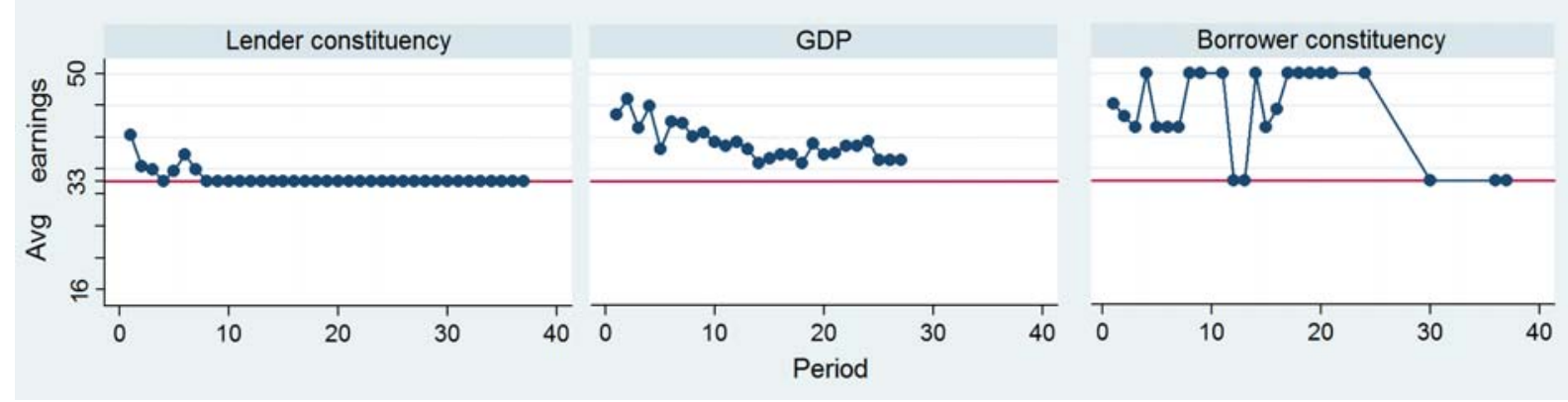

